\title{
Study on Financial Sustainability of Basic Endowment Insurance for Urban Employees in Sichuan Province*
}

\author{
Bing Li \\ School of Public Affairs and Administration \\ University of Electronic Science and Technology of China \\ Chengdu, China 610000
}

\author{
Juan Du \\ School of Public Affairs and Administration \\ University of Electronic Science and Technology of China \\ Chengdu, China 610000
}

\author{
Dongqiong Yang \\ School of Public Affairs and Administration \\ University of Electronic Science and Technology of China \\ Chengdu, China 610000
}

\begin{abstract}
With the increase of life expectancy of population and the deepening of aging, demand for pensions of the society is increasing constantly. At present, the basic endowment insurance for urban employees is in the process of changing from the "accounting on cash system" to the "fund accumulation system". The number of employees and retired people in Sichuan Province is increasing, and the pension is facing huge payment pressure. The financial sustainability of basic endowment insurance system has received widespread attention from the society. This paper analyzes the financial status of the basic endowment insurance for urban employees in Sichuan Province, and proposes countermeasures and suggestions to help strengthen the financial sustainable development of the basic endowment insurance for employees in the province to ensure the smooth realization of the interests of the insured employees.
\end{abstract}

Keywords-Sichuan Province; aging of population; basic endowment insurance for urban employees; financial sustainability

\section{INTRODUCTION}

The pension insurance system is closely related to the interests of each elderly person, and it is related to the basic life of the elderly and the endowment pension rights accumulated in young age. The pension insurance fund is the material basis of the whole system. To realize the sustainable development of the pension insurance system, it must first ensure that its finance has certain sustainability and ensure that the pension insurance income can meet the current and long-term pension payment needs.

The so-called financial sustainability of pension

*Fund: Key Research Base of Humanities and Social Sciences of Sichuan Education Department - Southwest Medical University "Sichuan Hospital Management and Development Research Center", Research on the Optimization of Community-Based Model of Elderly Nursing Care Combined with Medical Care Services (SCYG2019-02). insurance means that the pension insurance system has a long-term pension solvency while satisfying the sufficient pension benefits of the current retired employees, and will not pass the burden of payment to the next generation, that is, on the basis that the future pension payment needs not to be borne by the next generation, pension benefits can guarantee the normal life of the elderly [1] (Aaron, 2013). In other words, a sustainable pension system can meet both the pension payment of current retired employees and the committed level of future benefits for employees on the job without arbitrarily raising the contribution rate or reducing the level of pensions for employees [2] (Yang Yang, 2009). At the same time, the sustainable pension system should also have the ability to cope with the reality pressure of long life expectancy and the increasing number of the elderly [3] (Wang Xiaojun, 2012), and the level of pension payment can be adapted to the level of economic development [4] (Deng Liping, 2017).

At present, the number of people participating in basic endowment insurance for urban employees in Sichuan Province has continuously increased, reaching 23.351 million by the end of 2017 [5], and by the end of 2018, the population of the province aged 60 and over was 17.62 million, accounting for $21.13 \%$ of the whole population; the population aged 65 and above is 11.82 million, accounting for $14.17 \%$ [6], ranking the second in the country, and the aging of population is serious. The increase in the number of elderly people has reduced the number of people paying for pension insurance and the corresponding increase in the number of recipients which will undoubtedly put pressure on the payment of pensions and affect their financial sustainability. On such basis, this paper takes the basic pension insurance for employees in Sichuan Province as the research object. By analyzing the financial status of the basic endowment insurance for employees and the reasons for their existence, this paper proposes countermeasures and 
sustainability of the entire pension, as it reflects the CIEC of the pension system itself. province.

\section{CURRENT STATUS AND EVALUATION OF THE INCOME AND EXPENDITURE OF BASIC ENDOWMENT INSURANCE FOR URBAN EMPLOYEES IN SICHUAN PROVINCE}

\section{A. Financial Mechanism and Evaluation Indicators of Endowment Insurance Fund}

The basic pension insurance for urban employees has "two accounts", namely social pooling accounts and individual accounts. The social pooling account adopts the "accounting on cash" system. Based on the principle of horizontal balance, the unit pension paid by a company is used to pay the basic pension of the retired employees at the same time. In order to reduce the burden on enterprises, since May 1, 2019, the basic pension insurance rate in Sichuan Province has dropped from $19 \%$ to $16 \%$. The individual account implements the fund accumulation system. The insured employee pays a certain proportion of the endowment insurance premium to the social insurance institution every month, which is included in the personal account to protect the basic living needs of employee after retirement. The payment ratio is $8 \%$ of average monthly salary of the employee on the previous year.

Pension income and expenditure capacity (PIEC) [7] is an important indicator used to determine the financial sustainability of pension insurance. It refers to the ratio of total pension income to total expenditure for the whole year. In order to explain the problem more accurately, this indicator is generally split into two: one is the total pension income and expenditure capacity (TPIEC), that is, the ratio of total pension income to expenditure, that is, TPIEC $=$ Total income of endowment insurance fund / Total expenditure.

IF TPIEC $>1$, it indicates that the pension has a certain balance and has room for sustainable development.

IF TPIEC $<1$, It shows that pension over-expenditure, no balance, no sustainable development; the other is the collected income and expenditure capacity (CIEC), mainly refers to the ratio of income and expenditure of company and individual, that is, CIEC = Collected income $/$ Total expenditure.

IF CIEC $>1$, it means that the company and individual payment can meet the pension payment under the accounting on cash system.

IF CIEC $<1$, it means that the payment cannot be maintained in the current payment of the pension, and the income cannot cover the expenditure under the accounting on cash system.

According to the concept of financial sustainability of pension insurance, if the financial subsidies outside the system are needed to achieve balance of payments, the system itself is not sustainable. Therefore, compared with the TPIEC, the CIEC is a more accurate indicator to evaluate the

\section{B. Analysis of the Financial Status of the Basic Endowment Insurance for Urban Employees in Sichuan Province}

TABLE I. INCOME AND EXPENDITURE OF BASIC ENDOWMENT INSURANCE FOR URBAN EMPLOYEES IN SICHUAN PROVINCE, 2006-2017 (100 MILLION)

\begin{tabular}{|c|c|c|c|c|c|c|c|}
\hline Year & $\begin{array}{c}\text { Total } \\
\text { income of } \\
\text { endowment } \\
\text { insurance } \\
\text { fund }\end{array}$ & $\begin{array}{c}\text { Collected } \\
\text { income }\end{array}$ & $\begin{array}{c}\text { Financial } \\
\text { subsidy }\end{array}$ & $\begin{array}{c}\text { Total } \\
\text { expendit } \\
\text { ure }\end{array}$ & $\begin{array}{c}\text { Accum } \\
\text { ulated } \\
\text { balance }\end{array}$ & $\begin{array}{c}\text { Total } \\
\text { income and } \\
\text { expenditure } \\
\text { capacity }\end{array}$ & $\begin{array}{c}\text { Collected } \\
\text { income } \\
\text { and } \\
\text { expenditur } \\
\text { e capacity }\end{array}$ \\
\hline 2006 & 309.4 & 235.8 & 51.4 & 244.6 & 260.8 & 1.26 & 0.96 \\
\hline 2007 & 468.6 & 315.8 & 58.2 & 368.9 & 360.4 & 1.27 & 0.86 \\
\hline 2008 & 516.5 & 426.6 & 72.9 & 373.7 & 503.2 & 1.38 & 1.14 \\
\hline 2009 & 721.9 & 606.0 & 90.0 & 492.0 & 733.2 & 1.47 & 1.23 \\
\hline 2010 & 805.4 & 670.9 & 108.7 & 610.2 & 928.4 & 1.32 & 1.10 \\
\hline 2011 & 1085.9 & 870.3 & 135.7 & 754.2 & 1260.0 & 1.44 & 1.15 \\
\hline 2012 & 1132.0 & 901.4 & 169.0 & 927.7 & 1464.3 & 1.22 & 0.97 \\
\hline 2013 & 1392.9 & 1101.4 & 211.3 & 1107.6 & 1749.7 & 1.26 & 0.99 \\
\hline 2014 & 1576.8 & 1217.7 & 262.9 & 1313.2 & 2013.3 & 1.20 & 0.93 \\
\hline 2015 & 1680.7 & 1251.9 & 324.6 & 1527.6 & 2166.4 & 1.10 & 0.82 \\
\hline 2016 & 2743.0 & 1902.1 & 386.3 & 2679.9 & 2226.3 & 1.02 & 0.71 \\
\hline 2017 & 3293.0 & 2569.6 & 441.1 & 2276.4 & 3245.8 & 1.45 & 1.13 \\
\hline
\end{tabular}

${ }^{\text {a. }}$ Source: Statistical Communiqué on the Development of Human Resources and Social Security in Sichuan Province (2006-2017)

Total Pension Income and Expenditure Capacity

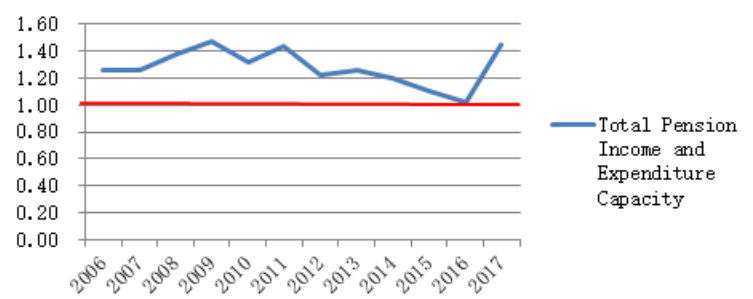

Fig. 1. TPIEC of Basic Endowment Insurance for Urban Employees in Sichuan Province, 2006-2017.

Collected income and expenditure capacity

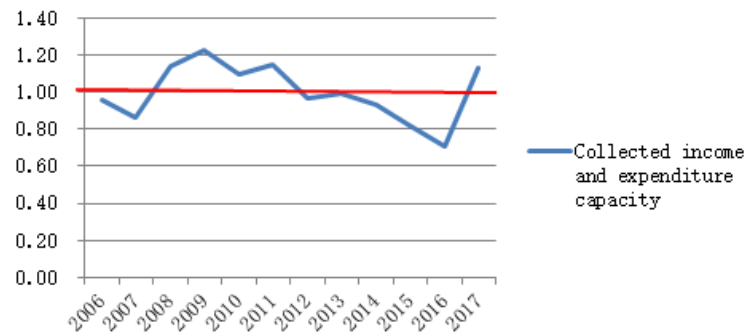

Fig. 2. CIEC of Basic Endowment Insurance for Urban Employees in Sichuan Province, 2006-2017.

According to the data in "Table I", the figure of TPIEC of Basic Endowment Insurance for Urban Employees in Sichuan Province and collection and TPIEC of Basic Endowment Insurance for Urban Employees in Sichuan Province is made. From the data of "Fig. 1" and "Fig. 2", it can be seen that: 1. From 2006 to 2017, the data of basic endowment insurance for urban 
employees in Sichuan Province showed a trend of increasing year by year; From the perspective of TPIEC, all TPIEC $>$ 1 ,it means that in the case of financial subsidies and "empty accounts" of personal accounts in the past years, the pensions are generally balanced, and the income during the year can meet the expenditures; From the perspective of the CIEC, the situation is fluctuating.

However, there are still two problems worthy of our attention here: 1. The TPIEC $>1$ is realized under the financial support, and the financial subsidies have been increasing over the years. China's basic endowment insurance for urban employees is an insurance system of payment type. According to conception of the financial sustainability of pension insurance, if the payment type system cannot rely on the payment within the system to achieve its financial balance, the system itself has great risks, and it indicates that the finance of the system itself may be unsustainable; on the other hand, this kind of system relying on external financial subsidy can only achieve the financial balance of the system in the short term. After all, the finance only bears the lowest responsibility, and if it continues for a long time, there will be huge hidden dangers. 2. The CIEC reflects the ability of income and expenditure under the accounting on cash model and does not reflect the reality of part of China's accumulation system. Under the accounting on cash system, the CIEC $>1$ does not maintain for a long period of time. If the individual account is fully implemented as required, the payment income alone will not be able to meet the payment needs of the year.

Therefore, it can be seen that the basic endowment insurance for urban employees in Sichuan Province has been unable to meet the payment over the years. Income from the payment alone cannot meet the payment demand, and the personal account operates as an "empty account". According to this development trend, there are also unsustainable financial risks in the future.

\section{CHALLENGES FOR FINANCIAL SUSTAINABILITY OF BASIC ENDOWMENT INSURANCE FOR EMPLOYEES}

\section{A. A Fundamental Challenge Brought by the Cost of System Transition Has Not Yet Been Resolved}

According to the analysis in the previous chapter, the basic endowment insurance for urban employees faces unsustainable risks, and personal account operates as an "empty account". The fundamental reason for this is that the cost of transition of urban employees' basic endowment insurance has not been resolved. The transition cost is the result of the explicitization of the implicit debt in the process of conversion of the endowment insurance from the "accounting on cash system" to the "capital accumulation system". Under the old system, the "elderly" did not have the accumulated funds of personal account, and the fund accumulation of personal account for "middle-aged people" was also seriously insufficient. Under the system of combining the unified account with the personal account, the implicit debt of their endowment insurance can be regarded as the personal account compensation and interest that they should receive in their past years of employment. Therefore, the pension of the "elderly" and the transitional pension of "middle-aged people" have become the transition cost of the endowment insurance system.

The system stipulates that this part of "hidden debt" is paid by the social pooling account funds, but the cost of transition costs is huge. The social pooling account not only has to pay this part of funds, but also needs to pay the basic pension of the retired employees. When the social pooling account funds are insufficient to pay, the funds in personal accounts are diverted, which has made the personal account operate as "empty account", and it will fundamentally affect the financial sustainability of the entire system. If the cost of transition cannot be fundamentally resolved, the risk of financial unsustainability will persist for a long time.

\section{B. Stage Challenges Brought About by Changes in the Age Structure of the Population}

The international community has set the aging standard as: the proportion of people aged 60 and over to the total population reaches $10 \%$ or the proportion of people aged 65 and over reaches $7 \%$. According to this standard, China has been an aging society since 1999 . In 2018, the population of 65 years old and above in Sichuan Province reached 11.82 million, accounting for $14.17 \%$ of the total population, which is aging population structure. If it is represented by the population age pyramid graph, it is a reduced population pyramid shape, that is, a tower with a wide top and a narrow bottom.

Population ageing not only contributes to an increase in the rate of ageing, but also to an increase in the Old-age Dependency Ratio (ODR), ODR is also called the dependency coefficient of the elderly population. In demography, ODR is an index to measure the burden level of the elderly population. It refers to the ratio of the number of the elderly population to the number of the working-age population in a certain population. Usually expressed as a percentage, it is used to indicate how many elderly people are to be burdened per 100 working-age people. The formula is,

\section{$\mathrm{ODR}=\mathrm{P} 65+/ \mathrm{P} 15-64 \times 100 \%$}

ODR is the Old-age Dependency Ratio, P65+ is the number of the elderly population aged 65 and over; P15-64 is the number of the working age population aged 15-64.

"Fig. 3" below compares the ODR in Sichuan Province from 2006 to 2017 with the CIEC in Sichuan Province from 2006 to 2017. Through "Fig. 3", we analyze the influence of ODR at different stages on the CIEC in Sichuan Province, so as to illustrate the impact of the change of population age structure on the balance of income and expenditure of pension funds. 
The 01d-age Dependency Ratio

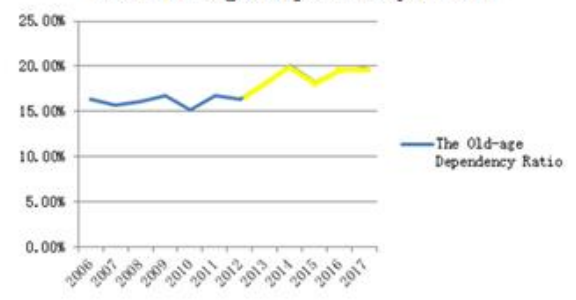

Collected income and expenditure capacity

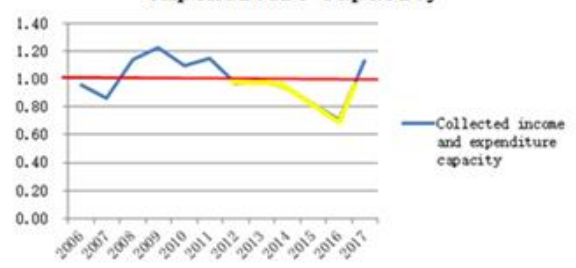

Fig. 3. The ODR in Sichuan Province from 2006 to 2017 and the CIEC in Sichuan Province from 2006 to 2017.

From "Fig. 3", we can see that: 1. ODR=P65+/ P15$64 \times 100 \%$, the CIEC means the ratio of income to expenditure. The contribution of 100 workers is unchanged, but the increase of dependency ratio means that the number of elderly people supported by 100 workers increases, that is, the increase of pension expenditure, which leads to the decline of pension collection ability. 2. The yellow part in the left of "Fig. 3" shows a sharp increase in the ODR from 2012 to 2017, while the yellow part in the right of "Fig. 3" shows CIEC $<1$ from 2012 to 2017. According to the definition of the ODR, when the ODR rises, the number of the old-age population supported by the working population increases. The pension insurance cost levied by workers is lower than that received by retired workers, to a certain extent, it shows that the old-age dependency ratio affects the ability of collection and payment.

The increase in the elderly population means that the oldage dependency ratio has increased, which means that the ratio of retired employees who receive pensions each year to the number of active employees who pay pensions increases, which will undoubtedly affect the balance of pension funds, and bring pressure to the payment of fundamental pensions. However, the age structure of the population has a phased characteristic. At present, the age structure of the elderly population in Sichuan Province is only temporary. With the death of the population borne at the peak of baby boom last century, the age structure of the population will also change. Therefore, the impact of changes in population age structure on the financial sustainability of pension insurance is temporary.

\section{Long-term Challenges Brought About by the Pension System}

The impact of the pension system itself on the income and expenditure of pension funds is long-term, so the impact on its financial sustainability is also long-term. It is mainly shown in the two aspects of "income" and "expenditure":

First, in terms of pension income, the efficiency of raising funds is low, and the basic pension insurance for employees has not yet achieved full coverage. In 2017, there were 48.72 million urban and rural employees in Sichuan Province, but the number of people participating in basic endowment insurance for urban employees was only 23.351 million, and the participation rate was only about $48 \%$. Among which, some rural employees participated in urban and rural residents' pension insurance. Even so, the basic pension insurance participation rate is only $87.4 \%$ [5]. It shows that a large part of the basic pension insurance is still not included, and most of them are migrant workers. The inefficiency of pension raising has enabled the reduction in the number of basic pensions to be paid, and the balance of the entire system has been affected by the deepening of the aging population and the increasing demand for payment.

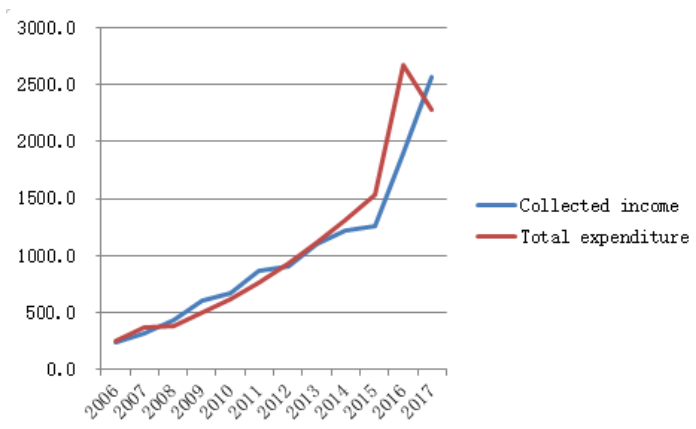

Fig. 4. Collected Income and Total Expenditure of Basic Endowment Insurance for Urban Employees in Sichuan Province,2006-2017(100 million).

Second, "Fig. 4" shows, in terms of expenditure, the payment method has brought certain payment pressure. From the income and expenditure data of 2006-2017, the collected income of pension insurance funds is lower than the total expenditure for 7 years. On the one hand, because the hidden debt liability is implicit. It is nominally borne by the state, but in fact most of it is paid by the social pooling account, and the funds in personal account will be diverted, so that the personal account is operated in an "empty" way. Therefore, the current system of "combining of unified social accounts and personal accounts" can be considered as an accounting on cash system in terms of financing methods. Compared with the past system, there is no substantial reform of financing and payment methods [8]. On the other hand, it is greatly connected with the fixed monthly number table for the current personal account. Personal account pension for retired employees $=$ total amount of individual accounts/the number of months, and the number of months is fixed. According to the system, after the pension of the individual account of the retired employee is received all, the remaining life cycle will still be calculated according to the same standard, and the short part will be supplemented by the social pooling account. As life expectancy increases, more individual personal account pensions need to be supplemented by social pooling accounts. Therefore, as time goes by, personal accounts and social pooling accounts will 
have mutual borrowing, which will inevitably affect their financial sustainability.

\section{SUGGESTIONS ON STRENGTHENING THE FINANCIAL SUSTAINABILITY OF URBAN EMPLOYEES' BASIC ENDOWMENT INSURANCE IN SICHUAN PROVINCE}

\section{A. Promoting the Development of Enterprises and Individuals to Strengthen the Raising Foundation}

Enterprises and individuals are the main bodies of payment for basic endowment insurance for employees. According to the responsibility of multiple entities, from the perspective of enterprises and individuals, it is possible to contribute to the realization of financial sustainability from the transformation of industrial structure and the improvement of employment rate.

1) Industrial structure transformation and upgrading: First, transform traditional industries, improve their independent innovation capabilities, and increase new economic energy through technological innovation. Through technological transformation and information reform of some traditional industries, the company will increase the added value of its products, form a new competitive advantage, and promote the transformation of enterprises from labor-intensive industries to technologyintensive industries. Second, vigorously develop emerging industries. In the era of rapid Internet development, it must actively promote the integration of the traditional real economy and the Internet and use technologies such as big data and artificial intelligence to promote the development of traditional manufacturing in the direction of digitalization and intelligence and make traditional industries from economics-driven to innovation-driven. Third, it should make the development of the service industry as a key industry for the transformation and upgrading of the industrial structure, the economic development from relying on the secondary industry to relying on the tertiary industry. The transformation and upgrading of the industrial structure can increase the market competitiveness of traditional industries, create more value for enterprises, and enable enterprises to pay more funds for employees' wages and endowment insurance premiums, thereby ensuring that the old-age insurance premiums are collected on time and in full, and enlarge the source of endowment insurance premiums.

2) Actively promoting employment: Employment is the basis of people's livelihood. To promote employment from the perspective of the government, first, it must improve the employment environment, formulate various policies and measures to promote employment and support employment, strengthen the employment management of enterprises, and protect the legitimate rights and interests of employees from the system. Second, actively support the development of emerging industries, use an industry to drive the development of related industries, and increase employment opportunities. The third is to actively implement vocational skills training, organize some targeted vocational skills training or vocational education, and help laid-off workers or migrant workers to improve their vocational skills and prepare for employment. Full and stable employment contributes to the stability and economic development of the entire society, increases the fiscal revenue of Sichuan Province, and enables more budgets to be used to subsidize pensions and make up for the cost.

\section{B. Improving the Fund Raising to Strengthen the Ability to Collect}

1) The government assumes the principal responsibility of transition of system: According to the theory of state responsibility and the theory of sharing responsibility of multiple subjects, the government, as the maker of the basic endowment insurance system, bears the responsibility of the basic endowment insurance to ensure the timely collection and payment of pensions. On the issue of transition costs of system and "empty accounts", the government must assume main responsibility and propose solutions or measures to solve the problem. Therefore, it is first necessary to count the number of the "elderly" and "middle-aged people" in a scientific way, and calculate the scale of the transition cost according to the current pension standard, clarify the amount of responsibility the government should bear, and enrich social security fund in various ways to supplement the gap in the "empty account" of personal accounts, and avoid the fuzzification of transition cost. In this regard, the government should continue to increase the intensity of financial subsidies, improve the system design, and make clear provisions on financial subsidies. If the problem of transition cost is solved, it will be conducive to the transformation of urban employee pension insurance from the accounting on cash system to the real fund accumulation system. The normal operation of the system helps to resist the payment pressure brought about by aging and reduce the risk of financial unsustainability.

2) Promoting full coverage of pension insurance and national coordination: To achieve full coverage of urban workers' basic endowment insurance, the key is to promote individual industrial and commercial households and flexible employment personnel to participate in insurance. First of all, it must increase policy propaganda, combine both online and off-line ways by using the network platform and going deep into the masses, and attract more people to participate in the insurance through lectures or distribution of brochures. In terms of implementation, it must focus on important aspect and achieve gradual promotion. Emphasis should be put on migrant workers and individual flexible employees with relatively stable employment companies, such as employees of various real estate and construction enterprises, shops, and supermarkets, strengthening the division of labor and cooperation between various departments, forming synergies and formulating specific plans. It should also make promotion actively from point to 
aspect, continuously promote the expansion of urban employees' basic endowment insurance coverage and improve the fund-raising efficiency from the breadth.

National coordination is the ultimate goal of the reform of the pension insurance system. In 2018, the state began to implement the central adjustment fund system, which is also considered to be the first step towards national coordination. In 2019, the budget for central transfer funds was nearly 500 billion yuan, and Sichuan's allocated amount is the largest to a maximum of 37.5 billion yuan, and the amount of funds paid was about 19.7 billion yuan, and Sichuan is undoubtedly benefited from this system. To achieve national coordination, the central and local governments need to define their respective division of responsibilities, break local thinking and local interests, and handle the relationship between overall interests and local interests [9]. The Sichuan provincial government must pay the funds in strict accordance with the proportion, implement the central system regulations, support the central government's policies from the overall interests, contribute to the nation's overall contribution, and improve the efficiency of raising pensions from the depth.

\section{Adjust the Fund's Payment Parameters in a Flexible Way so as to Share the Payment Pressure}

1) Designing flexibility monthly calculation: The number of months of payment is an important basis for the monthly pension of the individual account after the employee retirees. The specific design method can be as follows: first, it should determine a specific adjustment period, for example, 5 or 10 years as a cycle, and redesign the number of months according to the increase of life expectancy in the cycle; After the redesign of the payment month table, the personal account pension received by the employee on a monthly basis is will be calculated by the number of new calculations, that is, the remaining amount of the personal account pension is divided by the new number of months. However, if the life expectancy of the population does not increase significantly during the cycle, the current number of months of payment can continue to be used. The flexible month calculation table is in line with the current situation of China's population life expectancy. A reasonable month calculation table helps to achieve the balance of personal account pensions as well as the financial sustainability of personal account pensions. At the same time, individual account does not require a pooled account for subsidies, and it also helps to achieve a financial balance in the social pooling account.

2) Extending retirement age in a flexible way: According to the Life Cycle Hypothesis, the extension of life expectancy increases consumption after retirement, and higher requirements are placed on savings. Delayed retirement increases the time and amount of payment of endowment insurance premiums for employees and their companies, and shortens the length of time that the employees receive pensions, which is conducive to alleviating the imbalance between income and expenditure.
However, delayed retirement is not a one-step process. It is necessary to adopt a gradual delay scheme, which is extended by one month or several months first, and several years later to reach the final goal. In the implementation of the delayed retirement policy, certain incentives should be implemented according to the principle of financial actuarial balance, such as setting a minimum age limit for receiving full pensions. For employees who are delayed in retirement, each retirement delay can increase certain proportion of amount of the original pension. The longer the ratio, the higher the proportion, so as to motivate people to take the initiative to delay the age of receiving pensions. At the same time, the implementation of flexible retirement system can make pilot first. For some special groups or occupations, it can freely choose whether to extend working years. For example, those who work in heavy physical labor or work under high temperature and high pressure for a long time, their physical condition and affordability must be considered, and it must not blindly demand them to delay retirement.

\section{CONCLUSION}

The basic endowment insurance system for urban employees is an important part of China's basic social endowment insurance system. It is the most important institutional guarantee for the basic needs of employees after retirement. It not only relates to the living standards of retired employees, but also relates to the stability of the whole society. The financial sustainability of the basic endowment insurance for employees is of great significance for safeguarding the pension rights of retired employees and realizing the normal operation of the whole system, and measures must be taken to achieve this goal.

\section{REFERENCES}

[1] Aaron George Grech, Assessing The Sustainability of Pension Reforms in Europe, Centre for Analysis of Social Exclusion [D]. London School of Economics, 2013.15-16.

[2] Yang Yang. Research on Financial Sustainability of Pension Insurance System - Taking Shanghai Urban Pension Insurance as an Example [D]. Shanghai: Shanghai Academy of Social Sciences, 2009.4.

[3] Wang Xiaojun. Financial Sustainability of China's Aging Population and Social Endowment Insurance. 2012 Proceedings of China International Conference on Insurance and Risk Management [C], Qingdao, Shandong, 2012: 8.

[4] Nie Liping. Research on the Financial Sustainability of the Basic Endowment Insurance System of Institutions [J]. China Market, 2017, (23): 60-61.

[5] Sichuan Provincial Department of Human Resources and Social Security, 2017 Statistical Communiqué on the Development of Human Resources and Social Security in Sichuan Province. Http://www.sc.hrss.gov.cn/zwgk/zfxxgongkai/ghcwtj/rstj/201808/t20 180816_77112.html

[6] Sichuan Provincial Bureau of Statistics, Sichuan Provincial Population Statistics Bulletin 2018. Http://tjj.sc.gov.cn/tjxx/zxfb/201903/t20190319_277119.html

[7] Lin Yuming: An Outline of Social Security Sustainable Development [M], Beijing: Hualing Publishing House, 2005: 176. 
[8] Wang Xiaojun. Analysis of the Financial Sustainability of China's Endowment Insurance System [J]. Market and Population Analysis, 2002, (02): 26-29.

[9] Jing Peng, Chen Mingjun. Difficulties and Strategies of Marketoriented Investment Operation of Pension Insurance Funds [J]. Finance and Economy, 2018(10): 76-80. 